Full-text Available Online at www.bioline.org.br/ja
J. Appl. Sci. Environ. Mgt. September, 2006

Vol. 10 (3) 159- 162

\title{
Coagulation / flocculation process in the removal of trace metals present in industrial wastewater
}

\author{
${ }^{1}$ *AMUDA, OS; ${ }^{2}$ AMOO, IA; ${ }^{2}$ IPINMOROTI, KO; ${ }^{2}$ AJAYI, OO \\ ${ }^{1}$ Department of Pure and Applied Chemistry Ladoke Akintola University of Technology Ogbomoso, 210001, Nigeria \\ ${ }^{2}$ Department of chemistry Federal University of Technology, Akure, Nigeria.
}

\begin{abstract}
Attempts were made in this study to examine the effectiveness of polymer addition to coagulation process during treatment of a beverage industrial wastewater to remove some of its trace metals content such as lead, cadmium, total iron, total chromium, nickel and zinc. Experiments were conducted using the standard Jar test procedure to determine the performance of both ferric chloride and organic polymer (a non-ionic polyacrylamide) individually and ferric chloride-polymer combination. The dosages used for ferric chloride ranged from 0 to $500 \mathrm{mg} / \mathrm{l}$, whereas polymer dosages varied between 0 and $100 \mathrm{mg} / \mathrm{l}$. The (optimal) removal efficiency for total chromium in the wastewater was obtained at $300 \mathrm{mg} / \mathrm{l}$ for ferric chloride and $65 \mathrm{mg} / \mathrm{l}$ for polymer. Whereas for zinc and total iron, the optimal removal efficiencies were obtained at $500 \mathrm{mg} / \mathrm{l}$ for ferric chloride and $65 \mathrm{mg} / \mathrm{l}$ for polymer. Addition of ferric chloride resulted in significant removal of the metals reaching up to $91 \%, 72 \%$ and $54 \%$ of total chromium, zinc and total iron respectively while addition of polymer achieved $95 \%, 87 \%$ and $88 \%$ of total chromium, zinc and total iron respectively. Ferric chloride produced more voluminous and more compacted sludge than polymer. Combinations of ferric chloride and polymer at different ratio achieved better removal efficiencies of the metals in the range 84-97\% for total chromium, $69-90 \%$ for zinc and $69-92 \%$ for total iron, also less sludge was produced. Lead, cadmium and nickel were not detected in the raw wastewater. @JASEM
\end{abstract}

Since the early 1970s, there has been growing concern over the diverse effects of heavy metals on humans and aquatic ecosystems. Many heavy metals and their compound have been found that are toxic, while some are also subjected to biomagnifications (Viessman and Hammer, 1993; Gardea - Torresday et al. 1996 and Karvelas et al. 2003;). Environmental impact by heavy metals was earlier noticed to mostly connected to industrial sources (Karvelas et al. 2003). In recent years, metal production emissions have decreased in many countries due to legislation, improved cleaning technology and altered industrial activities. Today and in the future, dissipate losses from consumption of various metal containing goods are of most concern (Bergback et al. 2001). Therefore, regulations for heavy metal containing waste disposal have been tightened (FEPA, 1991). A significant part of anthropogenic emissions of heavy metals ends up in wastewater. Major industrial sources include surface treatment processes with elements such as $\mathrm{Cu}, \mathrm{Zn}, \mathrm{Ni}$ and $\mathrm{Cr}$, as well as industrial products that, at the end of their life, are discharged in wastes (Sun and Shi, 1998). Conventional processes in the field of wastewater treatment can be divided into two main phases: (1) generation of suspended solids from colloidal and dissolved solids by physical, chemical and biological means in addition to the already existing suspended solids, (2) separation of suspended solids by chemical and mechanical methods including sedimentation, flotation and filtration (Santarsiero et al. 1998).

Coagulation flocculation process has been employed by several workers (Sletten et al. 1995; Rossini et al. and 1999 Tatsi et al. 2003) in the treatment of wastewater for the removal of organic matter and trace metals. In this study, effectiveness of ferric chloride addition to treatment process during the wastewater treatment to reduce the trace metals (lead $-\mathrm{Pb}$, cadmium $-\mathrm{Cd}$, total iron $-\mathrm{Fe}^{2+}+\mathrm{Fe}^{3+}$, total chromium $-\mathrm{Cr}^{3+}+\mathrm{Cr}^{6+}$, nickel $-\mathrm{Ni}$ and Zinc - Zn) loading of the wastewater were investigated. The effect of a polymer on the reduction of the trace metals was examined. The influence of polymer addition to coagulation process was also examined. Finally, the relative sludge production after treatment was assessed.

\section{EXPERIMENTAL}

The study was designed to improve removal efficiency of trace metals (lead, cadmium, total iron, total chromium, nickel and zinc) in a beverage industrial wastewater.

Sampling And Sample Preparation: Samples of the wastewater were collected three times weekly for nine months between 9.00 and 3.00 p.m. of each sampling day from the pipe conveying all the wastewater out of the factory. Each time a sample was collected, the rate of flow was determined with the aid of a flow meter. At the end of the sampling period, a composite sample was made by adding together volumes of samples proportional to their rates of flow. The amount of wastewater generated daily from the factory was $2.2 \times 10^{5} 1$.

Sample Analysis: The raw wastewater was digested with aqua regia $\left(3: 1, \mathrm{HNO}_{3}: \mathrm{HCl}\right)$ to release its trace metal contents using standard methods (APHA AWWA - WEF, 1995), by transferring $100 \mathrm{ml}$ of well-mixed, acid preserved sample to a $250 \mathrm{ml}$ flask. A $10 \mathrm{ml}$ aqua regia was added. The flask was covered 
with a glass watch, placed on a hot plate and the solution cautiously evaporated to about $25 \mathrm{ml}$, making certain that the sample did not boil. The solution was cooled, the wall of the flask and the watch glass were washed down with deionized water, then, the solution was filtered to remove insoluble material that could clog the nebulizer. Analysis was carried out using atomic absorption spectrophotometer (Philips 9100X, England).

Coagulation Process: The conventional 'Jar test' procedure, was employed for coagulation, flocculation and sedimentation processes. The coagulant used is ferric chloride, while the coagulant aid (polymer) is a non - ionic polyacrylamide. The dosages of ferric chloride used ranged between 0 and $500 \mathrm{mg} / \mathrm{l}$, whereas polymer dosage varied between 0 and $100 \mathrm{mg} / \mathrm{l}$. A six beaker Jar test was set up at room temperature for each trial. Each beaker contained I l of the wastewater. The coagulant or polymer was added into the beakers, and the $\mathrm{pH}$ values were immediately adjusted to the preset values using $\mathrm{NaOH}$ or $\mathrm{HCl}$ as appropriate. Rapid mixing at $200 \mathrm{rpm}$ for 2 min was followed by gentle mixing at $30 \mathrm{rpm}$ for $3 \mathrm{~min}$, and the flocs formed were left to settle for $55 \mathrm{~min}$. The supernatant was withdrawn from the beaker by using a plastic syringe from a point located about $2 \mathrm{~cm}$ below the top of the liquid level of the beaker and digested using standard methods (APHA - AWWA - WEF, 1995) to release its trace metal contents and analyses were carried using atomic absorption spectrophotometer (Philips 9100X, England).

All chemicals used for the analytical determinations were of analytical grade. Raw samples and clarified samples have been repeatedly analyzed in order to validate/evaluate the produced results and analytical errors were less than $\pm 5 \%$.

\section{RESULTS AND DISCUSSION}

Total Metal Concentration Of The Wastewater: The total concentrations of trace metals determined in wastewater samples are presented in Table 1 along with data for conventional wastewater parameters. Total iron, total chromium and zinc were detectable in the wastewater sample. The relative abundance of metals in the wastewater sample followed the order: $\mathrm{Cr}<\mathrm{Zn}<\mathrm{Fe}$. Similar relative abundances and metal concentration levels have also been reported by other investigators for treated wastewater (Chipasa, 2003 and Karvelas et al. 2003). Lead, cadmium and nickel were not detectable in the wastewater sample.

Table 1: Mean \pm SD of trace metal concentration and other conventional parameters for raw wastewaters.

\begin{tabular}{lll}
\hline Parameters & Level & *(FEPA, 1991) \\
\cline { 2 - 3 } Total iron & $2.39 \pm 0.01$ & 20.00 \\
Cadmium & ND & $<1.00$ \\
Zinc & $1.52 \pm 0.01$ & $<1.00$ \\
Total chromium & $0.66 \pm 0.01$ & 0.10 \\
Nickel & ND & $<1.00$ \\
Biochemical Oxygen Demand (BOD) & $2.00 \pm 0.01$ & 30.00 \\
Total Dissolved solids (TDS) & $1.05 \pm 0.60$ & 2000.00 \\
Total solids (TS) & $18.04 \pm 1.00$ & NS \\
& & \\
pH (No unit) & $7.20 \pm 0.10$ & $6-9$ \\
Colour (Hazen unit) & $17.20 \pm 0.01$ & 7.00 \\
Turbidity (F.T.U) & $8.00 \pm 0.01$ & NS
\end{tabular}

*Guidelines for maximum concentration allowed for effluent discharge into surface water. All the parameters are in mg/l except otherwise stated. ND $=$ Not detectable. NS $=$ Not specified.

The Effect of Ferric Chloride Addition: Removal efficiency (\%) of the trace metals as a function of ferric chloride dose is presented in Fig 1. From this figure, it was found that the optimum dose of ferric 
chloride to remove total chromium was $300 \mathrm{mg} / \mathrm{l}$, whereas, the optimum dose of the coagulant to remove total iron and zinc was $500 \mathrm{mg} / \mathrm{l}$. Addition of $500 \mathrm{mg} / \mathrm{l}$ dose of ferric chloride resulted in 91, 54 and $72 \%$ removal efficiency of total chromium, total iron and zinc respectively.

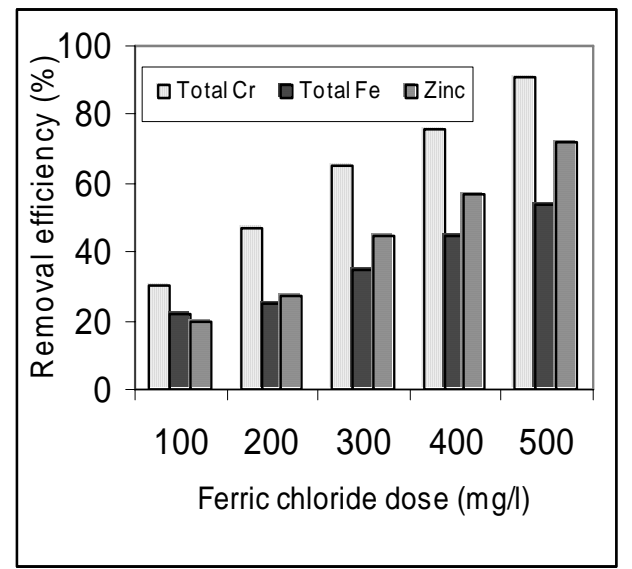

Fig. 1: Removal efficiencies of total chromium, total iron and zinc as functions of ferric chloride dose.

The Effect Of Polymer Addition: Figure 2 presents removal efficiency, (\%) of the trace metals as a function of polymer dose (mg/l). From this figure, it is shown that the optimum dose of the polymer to remove total chromium, total iron and zinc was $65 \mathrm{mg} / \mathrm{l}$. Increasing the dose of the polymer caused linear increase in the removal efficiency of the metals. Removal efficiency of total chromium reached $95 \%$ with the use of $85 \mathrm{mg} / \mathrm{l}$ polymer dose; this did not increase further with the use of $100 \mathrm{mg} / \mathrm{l}$ polymer dose. Removal efficiencies of total iron and zinc reached 80 and $74 \%$ respectively at $85 \mathrm{mg} / \mathrm{l}$, increasing the dose of the polymer to $100 \mathrm{mg} / \mathrm{l}$ caused removal efficiencies of total iron and zinc to reach 88 and $80 \%$ respectively.

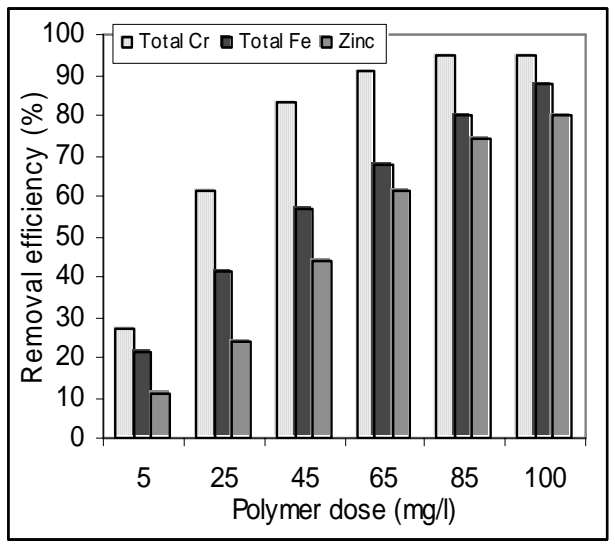

Fig. 2: Removal efficiencies of total chromium, total iron and zinc as functions of polymer dose.
The Influence of Polymer Addition to Coagulation Process: Polymers act as coagulant aids in the treatment of water and wastewater; they can also be used as primary coagulant for the same purpose (Vanotti and Hung, 1999). Many polymers are advantageous over chemical coagulants because they are safer to handle and they are easily biodegraded (Sievers et al. 1994 and Zhu et al. 2004). In this study, the dose of the polymer (a non-ionic polyacrylamide) was varied from 0 to $20 \mathrm{mg} / \mathrm{l}$. Figure 3 presents the removal efficiencies of total chromium total iron and zinc as functions of treatment conditions. These conditions in terms of coagulant dose and coagulant aid dose, were as follows: treatment 1: ferric chloride dose of $200 \mathrm{mg} / \mathrm{l}$ and polymer dose of $0 \mathrm{mg} / \mathrm{l}$; treatment 2: ferric chloride dose of $200 \mathrm{mg} / \mathrm{l}$ and polymer dose $5 \mathrm{mg} / \mathrm{l}$; treatment 3: ferric chloride dose of $200 \mathrm{mg} /$ and polymer dose of $10 \mathrm{mg} / \mathrm{l}$ and treatment 4 : ferric chloride dose of $200 \mathrm{mg} / \mathrm{l}$ and polymer dose of $20 \mathrm{mg} /$. From figure 3, it is shown that increasing dose of the polymer caused increase in the removal efficiencies of the metals. On addition of the polymer, total chromium removal efficiency reached $84 \%$ at $5 \mathrm{mg} / \mathrm{l}$ polymer dose and $200 \mathrm{mg} / \mathrm{l}$ ferric chloride dose, the total chromium removal efficiency increased to $93 \%$ as polymer dose was increased to $10 \mathrm{mg} / \mathrm{l}$, also, $97 \%$ total chromium removal efficiency was achieved when the polymer dose was further increased to $20 \mathrm{mg} / \mathrm{l}$. The removal efficiency of total iron was $69 \%$ with the use of $5 \mathrm{mg} / \mathrm{l}$ polymer dose and $200 \mathrm{mg} / \mathrm{l}$ ferric chloride dose, this increased to $85 \%$ and, further to, $92 \%$ when the dose of the polymer was increased to 10 and $20 \mathrm{mg} / \mathrm{l}$ respectively. For the removal of zinc, $69 \%$ removal efficiency was achieved with the use of $5 \mathrm{mg} / \mathrm{l}$ polymer dose, this increased to $80 \%$ at $10 \mathrm{mg} / \mathrm{l}$ polymer dose and further increased to $94 \%$ at $20 \mathrm{mg} / \mathrm{L}$ polymer dose when the dose of ferric chloride was maintained at $200 \mathrm{mg} / \mathrm{l}$.

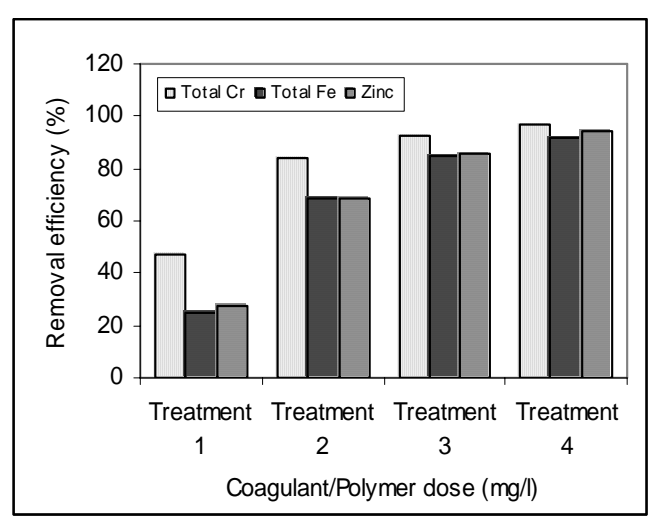

Fig. 3: The effect of ferric chloride and polymer on the removal efficiencies of total chromium, total iron and zinc. 
In this study, it was found that polymer addition to ferric chloride enhanced coagulation process even at various polymer doses. The same observation was reported by other workers (Santarsiero et al., 1998; Tatsi et al., 2003 and Zhu et al. 2004). Volume of sludge: In general, the amount and the characteristics of the sludge produced during coagulation - flocculation process depend on the coagulant used and on the operating conditions. In this study, the volume of sludge produced when only ferric chloride was used was voluminous but compacted. However the highest reduction in the volume of sludge (60\%) was obtained when the polymer was used as coagulant aid with ferric chloride. As can be seen from Table 2, the volume of sludge produced $(300 \mathrm{mg} / \mathrm{l})$ when ferric chloride was added dropped from 300mg/l to $120 \mathrm{mg} / \mathrm{l}$ when the non-ionic polymer was added as coagulant aid. This finding is in accordance with that of other investigators (Aguilar et al. 2005)

Table 2: Volume of sludge produced during coagulation flocculation process.

\begin{tabular}{|l|l|}
\hline Coagulant type and dose & $\begin{array}{l}\text { volume of } \\
\text { sludge }(\mathrm{ml} / \mathrm{l})\end{array}$ \\
\hline Ferric chloride(200mg/l) & 300 \\
\hline Ferric chloride: polymer(200:5mg/l) & 250 \\
\hline Ferric chloride: polymer(200:10mg/l) & 190 \\
\hline Ferric chloride: polymer (200:20mg/l) & 120 \\
\hline
\end{tabular}

Conclusion: A distinct decrease of the trace metal concentrations (increased removal efficiencies - \%) during the coagulation, flocculation process was obvious implying their removal from the wastewater. The optimum dose of ferric chloride to remove total chromium was $300 \mathrm{mg} / \mathrm{l}$ whereas; the optimum dose of ferric chloride to remove total iron and zinc was $500 \mathrm{mg} / \mathrm{l}$. A combinations of ferric chloride and polymer at different ratio achieved better removal of the metals in the range $84-97 \%$ for total chromium, $69-92 \%$ for total iron and $69-90 \%$ for zinc. The volume of sludge produced when only ferric chloride was used was voluminous but compacted; however, the highest reduction in the volume of sludge (60\%) was obtained when the polymer was used as coagulant aid with ferric chloride.

Acknowledgement: The authors acknowledged members of staff of Department of Chemistry, FUTA, Akure, members of staff of Department P/A Chemistry, LAUTECH, Ogbomoso and members of staff of Oyo State Water Corporation, Eleyele, Ibadan for their support during sampling and analysis.

\section{REFERENCES}

Aguilar, MI; Saez, J; Llorens, M; Soler, A; Ortuno, JF; Meseguer, V; Fuentes, A; (2005). Improvement of coagulation-flocculation process using anionic polycrylarmide as coagulant aid. Chemosphere. 59: (1) 4756.

Bergback, B; Johansson, K; Mohlander, U; (2001). Urban metal flow: a case study of Stockholm. Water. Air. Soil Pollut.: Focus 1: 3-24.

Chipasa B.K. (2003). Accumulation and fate of selected heavy metals in a biological wastewater treatment system. Water Manage. 23: (2), 135-143.

FEPA (1991). Guidelines and Standards for Environmental Pollution Control in Nigeria. Federal Environmental Protection Agency. 1-197

Gardea - Torresday, JL; Tang, L.; Salvador, JM; (1996). Copper adsorption by esterifies and unesterified fractions of sphagnum peat moss and its different humic substances. J. Hazard. Mater. 48: 191-206.

Karvelas, M; Katsoyiannis, A; Samara, C; (2003). Occurrence and fate of heavy metals in the wastewater treatment process. Chemosphere. 53: (10), 1201-1210.

Rossini, M; Garrido, JG; Galluzzo, M; (1999). Optimization of the coagulation - flocculation treatment: influence of rapid mix parameters. Water Res. 33: (8) 18171826.

Santarsiero, A; Veschetti, E; Donati, G; Ottaviani, M; (1998). Heavy metal distribution in wastewater from a treatment plant. Micro. Chem. J. 59: 219-227.

Sievers, DM; Jenner, MW; Hanna, M; (1994). Treatment of dilute manure wastewaters by chemical coagulation. Trans. ASAE., 37, 597-601.

Sletten, RS; Benjamin, MM; Horng, JJ; Ferguson, JF; (1995). Physical - Chemical treatment of landfill leachates for metal removal. Water Res. 29: (10), 2376 - 2386.

Sun, G; Shi, W; (1998). Sunflower stalks as adsorbent for the removal of metal ions from wastewater. Ind. Eng. Chem. Res. 37: 1324-1328.

Tatsi, AA; Zouboulis, AI; Matis, KA; Samara, P; (2003). Coagulation-flocculation pretreatment of sanitary land fill leachates. Chemosphere. 53: 737-744.

Vanoti, MB; Hung, PG; (1999). Solids and Nutrient removal from flushed swine manure using polyacrylamide. Trans ASAE., 42: 1833-1840.

Viessman, W; Hammer, MJ; (1993). Water Supply and Pollution Control. 5th ed., Harper Collins College Publishers, New York.

Zhu, K; Gamal El - Din, M; Maawad, AK; Bromley, D; (2004). Physical and chemical processes for removing suspended solid and phosphors from liquid swine manure. Environ. Technol. 25, 1177-1187. 